OPEN ACCESS

Edited by:

Sonja Ständer,

University Hospital Münster, Germany

Reviewed by:

Martin Metz,

Charité - Universitätsmedizin

Berlin, Germany

Luis Puig,

Autonomous University of

Barcelona, Spain

Laurent Misery,

Université de Bretagne

Occidentale, France

*Correspondence:

Kenii Kabashima

kaba@kuhp.kyoto-u.ac.jp

Specialty section:

This article was submitted to

Dermatology

a section of the journal

Frontiers in Medicine

Received: 06 December 2020

Accepted: 14 January 2021

Published: 12 February 2021

Citation:

Kabashima K and Irie H (2021)

Interleukin-31 as a Clinical Target for

Pruritus Treatment.

Front. Med. 8:638325.

doi: 10.3389/fmed.2021.638325

\section{Interleukin-31 as a Clinical Target for Pruritus Treatment}

\author{
Kenji Kabashima* and Hiroyuki Irie \\ Department of Dermatology, Graduate School of Medicine, Kyoto University, Kyoto, Japan
}

In recent years, the published literature has suggested the key involvement of the cytokine interleukin-31 (IL-31) in the symptomatology of pruritus, and both IL-31 and its receptor have become potential therapeutic targets for a range of pruritic diseases. Elevated levels of IL-31 or its receptor have been reported in the tissue or serum of patients with pruritic skin diseases, such as atopic dermatitis, prurigo nodularis, and psoriasis. Pruritus places a heavy burden on patients, and can have a negative impact on daily life, sleep, and mental health. Since current anti-pruritic treatments are often ineffective, affected patients are in urgent need of new therapies. As a result, drug development targeting the IL-31 pathway is evolving rapidly. To date, only nemolizumab, a humanized monoclonal antibody targeting the IL-31 receptor, has successfully completed late-stage clinical studies. This article will highlight our current clinical understanding of the role of IL-31 in pruritic disease, and explore recent progress in drug development as well as the anticipated future advances in this field.

Keywords: interleukin-31, interleukin-31 receptor, pruritus, itch, anti-IL-31, anti-IL-31RA, nemolizumab

\section{INTRODUCTION}

The T-cell-derived cytokine interleukin-31 (IL-31) was first identified in 2004 (1). Investigation in animal models suggested a role for IL-31 in the cutaneous and epithelial signs and symptoms observed in pruritus, skin inflammation, and airway hypersensitivity (1). Overexpression of IL-31 has been shown to be associated with promotion of sensory neuronal outgrowth (2) and stimulation (3), providing increased sensitivity to minimal itch-inducing stimuli which can result in sustained pruritus. Expression of IL-31 in skin is also associated with a profound repression of the filaggrin protein, which is critical in the differentiation of keratinocytes and skin barrier maintenance (4).

The receptor for IL-31 is a heterodimeric complex composed of IL-31 receptor A (IL-31RA) and the oncostatin M receptor (OSMR) $(1,5)$; the binding of IL-31 to its receptor activates cell signaling pathways including Jak/STAT, PI3K/AKT, and MAPK (5). In keratinocytes, IL-31 has been shown to induce cell cycle arrest, resulting in reduced proliferation, which in turn leads to atypical skin development, defects, and barrier dysfunction (4) (Figure 1). In other organs and physiologic systems, IL-31 has been linked to hematopoiesis and regulation of the immune response (5).

The recent published literature from both preclinical and clinical studies has suggested the key involvement of IL-31 in the symptomatology of acute and chronic pruritus (6-9). The objectives of this article are to highlight our current clinical understanding of the role of IL31 in pruritic diseases, and explore recent progress in drug development and the anticipated future advances in this field. Itching is a symptom that greatly impairs quality of life, and is often not well-controlled with current treatments $(10,11)$. In addition to the induction of itch, 


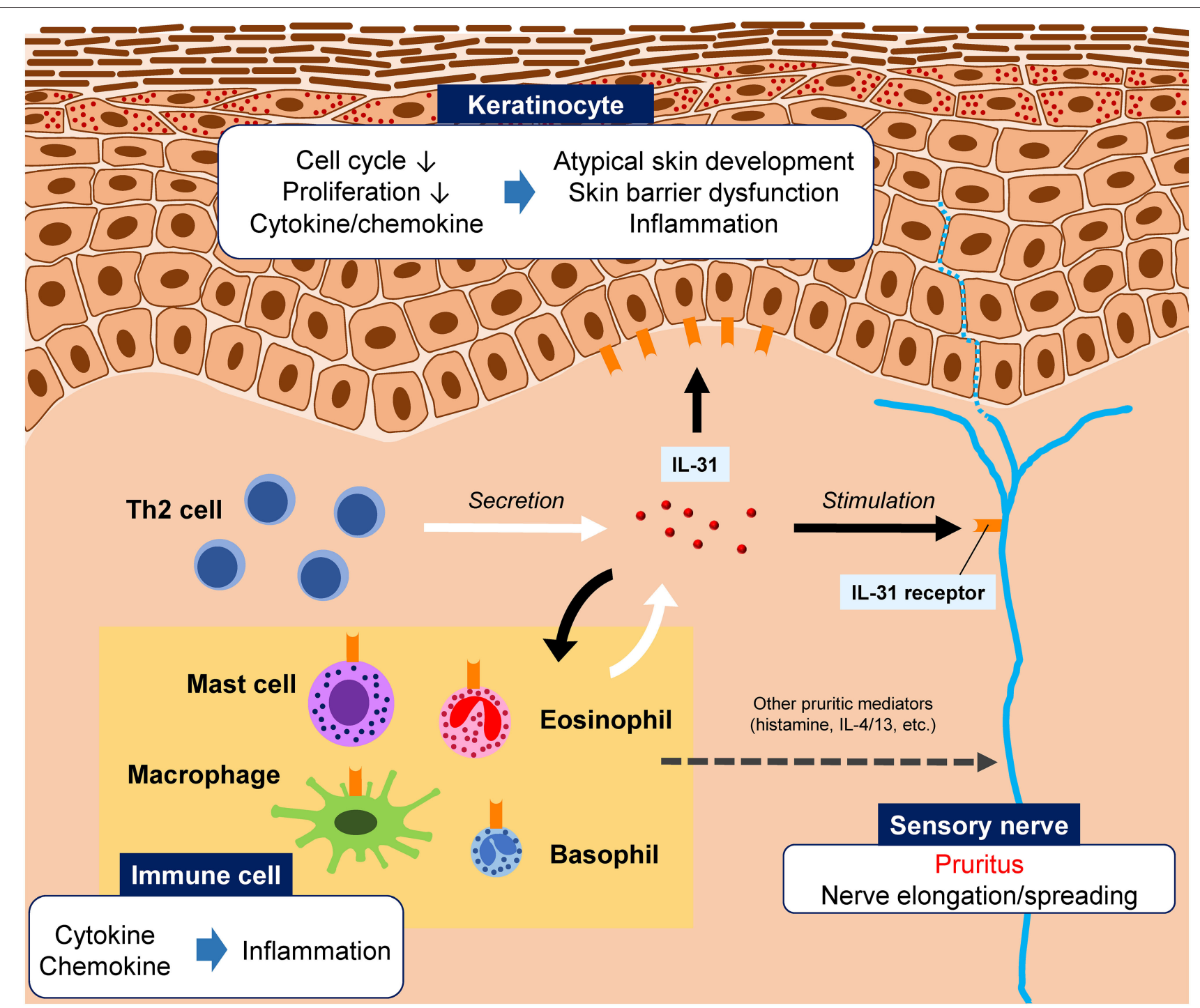

FIGURE 1 | Illustration of the hypothesized roles of interleukin (IL)-31 in pruritic skin diseases. IL-31 is primarily produced by T helper 2 (Th2) cells, although other innate immune cells can also produce IL-31. The IL-31 receptor is widely expressed by various cell types, including peripheral sensory nerves, epidermal

keratinocytes, and immune cells. IL-31 binding to its receptor on sensory neurons stimulates the nerve, causing pruritus. IL-31 is also involved skin barrier dysfunction and inflammation.

the IL-31 pathway also stimulates the release of inflammatory mediators and reduces the expression of molecules involved in the skin barrier, resulting in additional skin signs and symptoms $(4,12-14)$. As a result, both IL-31 and its receptor have become potential therapeutic targets for a range of pruritic diseases (14-18).

\section{THE BURDEN OF PRURITUS}

Itch is the most common complaint among patients who attend dermatology clinics, and for many patients, pruritic symptoms are intractable despite medication (19). In one study, 90\% of patients with chronic skin diseases reported that they had experienced pruritus, and that the intensity of itch was related to impairment in several areas of daily life, including sleep quality, work productivity, and mental health (20).

\section{Patient Burden}

Chronic pruritus has been shown to be as debilitating as chronic pain in terms of its impact on quality of life, with more severe itch having a more profound negative effect on daily life (21). In a recent study of 132 North American adults with chronic pruritus, health performance was found to be significantly reduced compared with normative controls $(p<0.001)(22)$. In a cross-sectional study of 602 US adults with atopic dermatitis, the most burdensome symptom was reported to be itch (54.4\%), 
and severe itch scores (measured using the patient-oriented scoring atopic dermatitis-itch scale) were associated with poor mental health scores (23). Suicidal ideation has been reported to be highly prevalent in patients with chronic pruritus (20), and several studies have shown that patients with pruritus are more likely to have anxiety and depression compared with non-pruritic controls $(20,24,25)$.

Pruritus also impairs sleep quality $(20,26-28)$, likely due to both the effects of scratching and underlying systemic inflammation (29). In one analysis, chronic pruritic dermatoses were found to be associated with increased nighttime awakenings (odds ratio 1.329-1.646) (30), while another study of patients with psoriasis found that pruritus significantly increased the difficulty of falling asleep $(p=0.031)$ (27). Thus, treatments for pruritus that can also improve sleep and quality of life are urgently needed.

\section{Economic Burden}

A study in North American adults calculated that chronic pruritus was associated with a mean of -5.5 quality-adjusted lifeyears per patient, which translated into an individual lifetime economic burden of US\$275, and a societal burden of almost US $\$ 90$ billion (22). Another study calculated median annualized costs of chronic pruritus of US $\$ 1067$ per patient (31). In addition to the costs of clinic consultations, referrals, laboratory tests, and prescription medication (32), the scratching behavior associated with pruritus may be associated with skin breakdown and increased infection, resulting in increased direct medical costs from attendance at emergency departments and hospitalization $(33,34)$. Indirect costs associated with pruritus include reduced work or school productivity (absenteeism and presenteeism), over-the-counter treatments, and the time required to apply topical agents or perform other self-treatment (31).

\section{IL-31 IN DISEASE}

In the past few years, an increasing number of researchers have postulated a link between IL-31 and the manifestations of various diseases, both dermatologic and non-dermatologic $(5,14,17,35)$. In addition to the development of itch (12), dysregulation of IL-31 and its receptor is thought to underlie alterations in the skin barrier (thickening or breakdown) (13), as well as autoimmune and inflammatory signs and symptoms (14). Individual diseases, and the putative role(s) of IL-31 in these disorders, are summarized below.

\section{Atopic Dermatitis}

In preclinical studies, mice treated with IL-31 exhibited skin lesions and scratching behavior similar to those seen in atopic dermatitis $(1,18,36)$, and treatments targeting IL-31 were found to reduce scratching $(37,38)$. In clinical studies, levels of serum IL-31 have been found to be elevated in patients with atopic dermatitis, compared with healthy individuals (39-41), and decreased after cyclosporin treatment (42); furthermore, IL-31 levels were shown to correlate with disease severity and pruritic symptoms (39-41).
IL-31 receptors are expressed constitutively on the surface of keratinocytes, eosinophils and small diameter neurons (43). Keratinocyte levels of IL-31RA expressed in atopic dermatitis lesions have been shown to be higher than those of normal skin in healthy subjects $(44,45)$, while no difference in levels of OSMR has been observed (44), emphasizing the greater importance of IL-31RA in the pathogenesis of the disease.

\section{Prurigo Nodularis}

Prurigo nodularis, a chronic disease presenting as one or more hyperkeratotic papules which are intensely pruritic, results in a difficult to treat itch-scratch cycle, and causes sleep disturbances and psychiatric comorbidities in affected patients (46). An analysis of skin samples from patients with various chronic inflammatory skin diseases revealed that the highest levels of IL31 were located in lesional skin from individuals with prurigo nodularis, with an elevation of IL-31 mRNA almost 50-fold higher than that of skin from healthy individuals (47).

\section{Psoriasis}

Like atopic dermatitis, psoriasis is an inflammatory skin disease affecting millions of people worldwide, and can have a negative impact on the mental health and quality of life of patients (48). A role for IL-31 in the pathogenesis of psoriasis has been suggested (49), with elevated levels of serum IL-31 observed in psoriatic patients compared with controls (8). Patients with early-onset psoriasis have greater levels of Il-31 gene induction compared with healthy controls, and even compared with patients with atopic dermatitis (50). However, the data are inconsistent; other studies have failed to show elevated levels of IL-31 in psoriasis (51), or any association between IL-31 and pruritus intensity in psoriatic patients (52).

\section{Cutaneous T-Cell Lymphoma (CTCL)}

CTCL comprises a heterogeneous group of diseases arising from the $\mathrm{T}$ cells involved in tumor responses (53). Most patients (around $88 \%$ ) with CTCL are affected by pruritus (54), and studies have demonstrated elevated levels of IL-31, IL-31RA, and OSMR $\beta$ within the epidermis of affected patients (54), as well as increased serum IL-31 levels $(55,56)$. In one analysis, levels of IL31 mRNA appeared to be correlated with the severity of pruritus in CTCL patients (57), although data from another study did not support this contention (58). It has been hypothesized that IL31 may induce epidermal neoplastic $\mathrm{T}$ cells and keratinocytes to transmit itch, indirectly affecting sensory nerves (54). Although IL-31 appears to have a role in pruritus in CTCL, there is conflicting evidence as to whether it plays a larger role in the pathogenesis of CTCL itself $(56,58,59)$. However, of note, chronic prurigo has also been reported in cases of Hodgkin lymphoma (HL) (60), and a study in HL patients demonstrated elevated IL-31 in HL cells and in the immune cells infiltrating affected lymph nodes (61). Another recent study showed that plasma concentrations of IL-31 decreased in HL patients entering remission (62); taken together, these findings suggest that IL-31 may contribute to immune suppression in HL, and may indicate a similar role in CTCL. 


\section{Other Pruritic Disorders Uremic Pruritus}

Uremic pruritus occurs in patients with chronic kidney disease, and is characterized by intractable systemic itching, often without any other obvious cutaneous symptoms $(63,64)$. IL-31 may play a role in the development and maintenance of uremic pruritus in patients receiving hemodialysis (65). In a study of 178 hemodialysis patients, significantly higher levels of IL-31 were recorded in patients with pruritic symptoms compared with those without $(p=0.04)(66)$.

\section{Cholestatic Pruritus}

The development of cholestatic pruritus, which is found in patients with primary biliary cirrhosis, primary sclerosing cholangitis, and intrahepatic cholestasis of pregnancy (ICP) (67, 68), may also be linked to an elevation in levels of IL-31. In a small-scale study, median levels of serum IL-31 were found to be significantly higher in 13 pregnant women with ICP than in the control group of 26 pregnant women without ICP $(p=0.004)$; in addition, levels of IL-31 showed a direct correlation with liver transaminase levels (68). Of note, the IL-31 pathway has also been reported to be involved in the pathogenesis of hepatitis B virusrelated liver cirrhosis (69), potentially suggesting a wider role for IL-31 in hepatic health.

\section{Bullous Pemphigoid and Chronic Urticaria}

In autoimmune skin diseases, such as bullous pemphigoid and chronic urticaria, IL-31 may be involved in both pruritus and immunomodulation, potentially underpinning the IgEassociated pathophysiology involved in these diseases (35). Skin (70) and serum (71) samples from patients with chronic urticaria have been shown to have high levels of IL-31, and following stimulation, basophils from normal skin also demonstrated increased IL-31 expression, resulting in the release of proinflammatory cytokines and the induction of chemotaxis (70). In bullous pemphigoid, it is eosinophils that appear to be the major source of IL-31 $(72,73)$. Another, related, condition in which IL31 has been implicated is pemphigus herpetiformis (dermatitis herpetiformis) $(74,75)$.

\section{Allergic Contact Dermatitis (ACD)}

Around $20 \%$ of adults worldwide are affected by ACD, either as a result of sensitivity to everyday products (particularly fragrances) or via exposure to allergens within their work environment (76). A role for IL-31 in ACD has been postulated, with elevated serum levels of IL-31 found in ACD patients compared with controls (77). However, the precise details remain to be clarified, as a preclinical study has suggested that IL-31 may be associated only with pruritus, but not inflammation in contact hypersensitivity (78).

\section{Dermatomyositis}

Dermatomyositis is a chronic, inflammatory, autoimmune disease characterized by cutaneous involvement (79). Although symptoms can be heterogeneous, pruritus is a common manifestation (80). A recent analysis indicated that gene and protein expression of IL-31 and IL-31RA was increased in dermatomyositis lesions compared with non-lesional skin and normal control skin (81).

\section{Chronic Pruritus of Unknown Origin (CPUO)}

CPUO is the nomenclature used to describe the presentation of chronic itch which has no distinct etiology (82). The pathophysiology of CPUO remains unclear (10), but patients with CPUO have been shown to have elevated serum levels of IL-31 compared with healthy subjects (7). In regression analysis the presence of CPUO was found to be independently and significantly associated with serum Il-31 levels $(p<0.001)(7)$.

\section{Other Dermatologic Conditions}

Other dermatologic conditions in which IL-31/IL-31R have been implicated include lichen planus (83), cutaneous (lichen) amyloidosis (84-86), statis dermatitis (87), scleroderma (88), and the itch associated with wound healing (89). However, detailed data are lacking, and further studies are necessary to fully determine the role of IL-31 in the pathophysiology and symptomatology of each of these conditions.

\section{Non-pruritic Diseases Allergic Asthma}

Expression of IL-31RA is tightly regulated within the various cells found in the lung (90), and in vitro studies have suggested IL-31-stimulation of bronchial cells results in the production of proinflammatory cytokines, growth factors, and chemokines, which could contribute to the inflammation, tissue damage and pulmonary remodeling observed in asthma (91). Studies have shown that levels of IL-31 mRNA and protein are elevated in patients with allergic asthma (92), and expression of both IL31 and IL-31R are increased in the bronchial tissue of patients with severe asthma (93). Serum IL-31 levels were also found to positively correlate with asthma severity and IgE levels (93).

\section{Inflammatory Bowel Disease (IBD)}

Analysis of colonic biopsies from patients with Crohn's disease and ulcerative colitis found that IL-31, IL-31RA, and OSMR mRNA expression was increased in inflamed lesions compared with non-inflamed lesions (94). There has been a great deal of recent interest in the possibility of targeting OSM in IBD (95), but IL-31 does not currently appear to be a drug target for this condition.

\section{Osteoporosis}

Numerous inflammatory cytokines have been demonstrated to be involved in bone remodeling, and there are both in vitro and clinical observations which suggest a role for IL-31 in the development of osteoporosis (96). In a study in postmenopausal females, patients with osteoporosis exhibited elevated levels of serum IL-31 compared with healthy controls $(p<0.049)$ (97). Notably, higher levels of IL-31 were associated with increased age, suggesting an association between Th2 cytokine overexpression and bone resorption in senile osteoporosis (98). 


\section{CURRENT CLINICAL STATUS OF ANTI-IL-31 THERAPIES}

Since current anti-pruritic treatments are often ineffective (99, $100)$, affected patients are in urgent need of new therapies (101, 102). As a result, drug development targeting the IL-31 pathway is evolving rapidly. An overview is provided in Table $\mathbf{1 .}$

\section{Anti-IL-31}

Two agents targeting IL-31 have been developed thus far, one intended for clinical use and one for veterinary use.

\section{BMS-981164}

BMS-981164 was an anti-IL-31 monoclonal antibody targeting circulating IL-31 being developed by Bristol-Myers Squibb. A two-part, phase I, single-dose, dose-escalation study was conducted between 2012 and 2015 to explore the safety and pharmacokinetic profile of BMS-981164 (NCT01614756). The study design was randomized, double-blind, placebo-controlled, and the drug was administered as both SC and IV formulations $(0.01$ to $3 \mathrm{mg} / \mathrm{kg}$ ) to healthy volunteers (part 1) and adults with atopic dermatitis (part 2). Adult subjects in part 2 were required to have at least moderate atopic dermatitis (assessed by Physician Global Assessment rating of $\geq 3$ on a scale of 0 to 5) and pruritus severity of at least 7 of 10 on a visual analog scale.

To date, no results from this study have been released. As of 2016, BMS-981164 was no longer listed in the development pipeline of Bristol-Myers Squibb, and no new trials have been announced.

\section{Lokivetmab}

The amino acid sequence of IL-31 has been shown to vary across species, with the human sequence showing $>80 \%$ homology with isoforms isolated from several species of monkey, but decreased similarities with canine (54\%) and murine (30-31\%) forms $(106,107)$. Despite this variation, IL-31 has been linked with the development of pruritus in multiple mammalian species $(1,106,108)$.

Lokivetmab (ZTS-00103289) is a caninized IL-31 monoclonal antibody that has demonstrated efficacy in reducing pruritus in dogs, in various conditions including atopic dermatitis (109111), and mastocytosis (112). Although not suitable for use in humans, data accruing from this agent could inform the future development of other novel anti-IL-31 therapeutic agents.

\section{Anti-IL-31RA}

To date, the only agent targeting IL-31RA is nemolizumab, a subcutaneously-administered humanized monoclonal antibody manufactured by Chugai Pharmaceutical Co., Ltd., and being developed by Maruho Co., Ltd., in Japan and Galderma SA in Europe and the US $(106,113)$. This has been the most successful strategy to date, with nemolizumab being the only agent targeting the IL-31 pathway to reach phase 3 development. In addition to its effects on pruritus, nemolizumab has also been evaluated for its effectiveness in improving sleep, daily functioning, and quality of life in patients with atopic dermatitis (103).

\section{Nemolizumab}

In early-phase clinical studies involving adults with moderateto-severe atopic dermatitis, nemolizumab showed efficacy in reducing both pruritus and also the skin signs of atopic dermatitis (113-116). In the first in-human study, a single administration decreased pruritus, sleep disturbance, and use of topical hydrocortisone, and was well tolerated (113).

In a phase 2, double-blind, placebo-controlled, 12-week trial, adults with moderate-to-severe atopic dermatitis that was inadequately controlled by topical treatments were randomly assigned to receive subcutaneous nemolizumab (at a dose of $0.1,0.5$, or $2.0 \mathrm{mg} / \mathrm{kg}$ ) or placebo every 4 weeks (Q4W), or nemolizumab $2.0 \mathrm{mg} / \mathrm{kg}$ Q8W (115). The primary end point was the percentage improvement from baseline in the score on the pruritus visual analog scale (VAS) at Week 12, and nemolizumab Q4W was shown to significantly improve pruritus at Week 12 ( $p<0.01$ for all doses vs. placebo). Adverse events occurred at similar frequencies with nemolizumab and placebo; however, more nemolizumab-treated patients reported exacerbations in atopic dermatitis and peripheral edema.

In the long-term (52-week) double-blind extension of the phase 2 study (114), the improvements in the pruritus VAS and Eczema Area and Severity Index (EASI) scores from baseline to Week 12 were maintained or increased from Week 12 to Week 64 with nemolizumab treatment. No new or lateonset safety concerns were identified. The mean decrease in Work Productivity and Activity Impairment-Atopic Dermatitis questionnaire score from baseline at Week 12 was greater in nemolizumab-treated patients compared with those receiving placebo for work productivity and ability to perform daily activities (117). Improvements were sustained through Week 64 of the study.

In a phase $2 \mathrm{~b}$, randomized, double-blind, placebo-controlled, dose-ranging study of 24 weeks' duration, nemolizumab produced rapid improvements in cutaneous inflammation and pruritus, which were maintained throughout the treatment period, and had an acceptable safety profile (116).

A 16-week, double-blind, phase 3 trial in patients with atopic dermatitis and moderate-to-severe pruritus and an inadequate response to topical agents was recently conducted in Japan (103). Patients were randomly assigned 2:1 to receive subcutaneous nemolizumab $60 \mathrm{mg}$ or placebo Q4W plus concomitant topical corticosteroids/topical calcineurin inhibitors (TCS/TCI). The primary end point (mean percent change in pruritus VAS from baseline to week 16) was reduced by $-42.8 \%$ in the nemolizumab group and $-21.4 \%$ in the placebo group (difference, $-21.5 \%$; $p$ $<0.001$ ). Secondary efficacy data indicated that nemolizumab provided additional benefits to patients, with a reduction in the EASI score of $-45.9 \%$ (vs. $-33.2 \%$ with placebo), more patients with a score of 4 or less on the Dermatology Life Quality Index (40 vs. $22 \%$ with placebo), and more patients with a score of 7 or less on the Insomnia Severity Index (55 vs. $21 \%$ with placebo). Rates of adverse events were similar between treatment groups. Cytokine abnormalities (increased thymus and activation-regulated chemokine level) occurred in the nemolizumab group after treatment; however, there was no association with the EASI score. 
TABLE 1 | Summary of anti-IL-31 therapies in development.

\begin{tabular}{|c|c|c|c|c|c|}
\hline Agent & Target & Drug attributes & Disease & $\begin{array}{l}\text { Highest development } \\
\text { stage }\end{array}$ & Key outcomes \\
\hline BMS-981164 & IL-31 & $\begin{array}{l}\text { Monoclonal antibody, } \\
\text { administered SC and } \\
\text { IV }\end{array}$ & $\begin{array}{l}\text { Atopic } \\
\text { dermatitis }\end{array}$ & Phase 1 & - Unknown (completed 2015 but unpublished) \\
\hline Lokivetmab & IL-31 & $\begin{array}{l}\text { Caninized monoclonal } \\
\text { antibody, administered } \\
\text { SC }\end{array}$ & $\begin{array}{l}\text { Canine atopic } \\
\text { dermatitis, } \\
\text { canine } \\
\text { mastitis }\end{array}$ & N/A (veterinary use only) & - Reduces pruritus in dogs \\
\hline \multirow[t]{2}{*}{ Nemolizumab } & IL-31RA & $\begin{array}{l}\text { Humanized } \\
\text { monoclonal antibody, } \\
\text { administered SC }\end{array}$ & $\begin{array}{l}\text { Atopic } \\
\text { dermatitis }\end{array}$ & $\begin{array}{l}\text { Phase } 3 \text { (administered } \\
\text { with concomitant } \\
\text { TCS/TCI) (103) }\end{array}$ & $\begin{array}{l}\text { - Mean percent change in pruritus VAS from baseline to week } \\
\text { 16: nemolizumab-42.8\%, placebo-21.4\% (difference, } \\
-21.5 \% ; p<0.001 \text { ) } \\
\text { - Reduction in EASI score: nemolizumab }-45.9 \% \text {, placebo } \\
-33.2 \% \\
\text { - Score of } \leq 4 \text { on DLQI: nemolizumab } 40 \% \text {, placebo } 22 \% \\
\text { - Score of } \leq 7 \text { on ISI: nemolizumab } 55 \% \text {, placebo } 21 \% \\
\text { - Rates of adverse events were similar between } \\
\text { treatment groups }\end{array}$ \\
\hline & & & $\begin{array}{l}\text { Prurigo } \\
\text { nodularis }\end{array}$ & Phase 2 (104) & $\begin{array}{l}\text { - Percent change in the mean peak pruritus NRS score from } \\
\text { baseline to week 4: nemolizumab-53.0\%, placebo }-20.2 \% \\
\text { (difference }-32.8 \% ; p<0.001 \text { ) } \\
\text { - Similar trends observed for secondary outcomes } \\
\text { - The overall tolerability profiles were comparable between } \\
\text { treatment groups }\end{array}$ \\
\hline \multirow[t]{2}{*}{ Vixarelimab } & OSMR & $\begin{array}{l}\text { Monoclonal antibody, } \\
\text { administered SC }\end{array}$ & $\begin{array}{l}\text { Prurigo } \\
\text { nodularis }\end{array}$ & Phase 2a (105) & $\begin{array}{l}\text { - LSM change in weekly average WI-NRS from baseline at } \\
\text { Week } 8 \text { : vixarelimab-50.6\%, placebo-29.4\% (difference } \\
21.1 \% ; p=0.035 \text { ) } \\
\text { - No dose-limiting AEs, no serious AEs, no atopic } \\
\text { dermatitis flares }\end{array}$ \\
\hline & & & $\begin{array}{l}\text { Chronic } \\
\text { pruritic } \\
\text { diseases }^{a}\end{array}$ & Phase 2 (105) & $\begin{array}{l}\text { - Plaque psoriasis: LSM change in WI-NRS from baseline to } \\
\text { Week 8: vixarelimab }-66.5 \% \text {, placebo }-29.0 \%(p=0.012) \text {. } \\
\text { - Chronic idiopathic pruritus: LSM change in WI-NRS from } \\
\text { baseline to Week 8: vixarelimab-52.4\%, placebo }-48.8 \% \\
(p=0.813) \text {. } \\
\text { - No formal statistical analysis in lichen simplex chronicus, } \\
\text { chronic idiopathic urticaria, and lichen planus due to small } \\
\text { patient numbers ( }<5 \text { per group) } \\
\text { - No dose-limiting AEs }\end{array}$ \\
\hline
\end{tabular}

aIncluding plaque psoriasis, chronic idiopathic pruritus, lichen simplex chronicus, chronic idiopathic urticaria, or lichen planus.

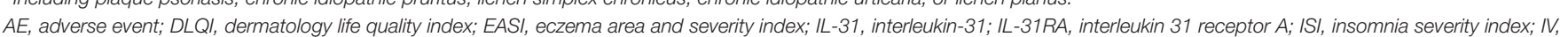

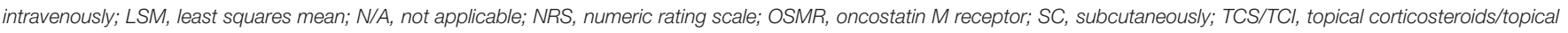
calcineurin inhibitors; VAS, visual analog scale; WI-NRS, worst-itch numeric rating scale.

Nemolizumab has also demonstrated efficacy in the reduction of pruritus in patients with moderate-to-severe prurigo nodularis and severe pruritus (104). A 12-week, randomized, double-blind, placebo-controlled, phase 2 trial of nemolizumab $0.5 \mathrm{mg} / \mathrm{kg}$ administered at baseline, week 4 , and week 8 was conducted. The primary outcome (percent change from baseline in the mean peak score for pruritus on the numeric rating scale at week 4) was reduced by $-53.0 \%$ with nemolizumab vs. $-20.2 \%$ in the placebo group (difference $-32.8 \% ; p<0.001$ ). Secondary outcomes followed the same trend as the primary outcome. Nemolizumab was associated with gastrointestinal symptoms (abdominal pain and diarrhea; $21 \%$ vs. placebo $14 \%$ ) and musculoskeletal symptoms ( $18 \%$ vs. placebo 14\%); however, the overall tolerability profile was comparable with that of placebo and only 2 patients in each group discontinued treatment due to adverse events.

\section{Anti-OSMR}

Although modulation of the oncostatin $\mathrm{M}$ receptor is potentially of clinical interest, to date, only one drug which directly targets OSMR has been evaluated in clinical trials, and few published details are available.

\section{Vixarelimab (KPL-716)}

Vixarelimab is a monoclonal antibody being developed for the treatment pf prurigo nodularis by Kiniksa Pharmaceuticals Corp; it simultaneously targets both the OSMR $\beta$, which mediates signaling of IL-31, and the oncostatin M pathways (105). It is subcutaneously administered as a loading dose of $720 \mathrm{mg}$ followed by weekly injections of $360 \mathrm{mg}$.

In a randomized, double-blind, placebo-controlled phase $2 \mathrm{a}$ clinical trial of vixarelimab in 49 patients with prurigo nodularis, vixarelimab met its primary efficacy endpoint of the reduction in weekly average Worst-Itch Numeric Rating Scale (WI-NRS) 
from baseline at Week 8. At Week 8, the least squares mean change from baseline in weekly average WI-NRS was $-50.6 \%$ in the vixarelimab treatment group compared with $-29.4 \%$ in the placebo group (mean difference $21.1 \% ; p=0.035$ ).

In an exploratory phase 2 study, the efficacy of vixarelimab was evaluated in patients with other chronic pruritic diseases, including plaque psoriasis, chronic idiopathic pruritus, lichen simplex chronicus, chronic idiopathic urticaria, or lichen planus. In the plaque psoriasis cohort, the least squares mean change in WI-NRS from baseline to Week 8 was $-66.5 \%$ in the vixarelimab group and $-29.0 \%$ in the placebo group $(p=0.012)$. In the chronic idiopathic pruritus cohort, the changes were-52.4\% with vixarelimab and $-48.8 \%$ with placebo $(p=0.813)$. Due to small numbers of patients ( $<5$ per group) with lichen simplex chronicus, chronic idiopathic urticaria, and lichen planus, no formal statistical analysis was performed, but the data were reported to show an encouraging effect of treatment.

In both studies, vixarelimab was said to be well-tolerated, with no dose-limiting adverse events; moreover, no serious adverse events or atopic dermatitis flares were noted in the phase $2 \mathrm{a}$ study. However, to date, the only available information has been provided on the manufacturer website (105); no publications are available and the data have not been peer-reviewed. In addition, no phase 3 studies have yet been planned.

\section{DISCUSSION}

Pruritus affects patients of all ages, races, and sex, and can have an extremely negative impact on their quality of life (118). Given that many patients are refractory to available treatments $(99,100)$, it is important to develop new drugs to improve clinical and social outcomes.

Based on its roles in the development of itch, skin deficits, and inflammation $(4,12-14,119)$, targeting the IL-31 pathway is a logical step in the development of new pharmacologic agents against pruritus. To date, however, only the anti-IL-31RA antibody nemolizumab has progressed to late-stage clinical trials. Based on the positive results of the recent phase 3 clinical trial of nemolizumab plus concomitant topical agents to treat patients with atopic dermatitis and moderate-to-severe pruritus (103), and the efficacy benefits shown in reducing pruritus in patients with moderate-to-severe prurigo nodularis (104), this

\section{REFERENCES}

1. Dillon SR, Sprecher C, Hammond A, Bilsborough J, Rosenfeld-Franklin M, Presnell SR, et al. Interleukin 31, a cytokine produced by activated $\mathrm{T}$ cells, induces dermatitis in mice. Nat Immunol. (2004) 5:75260. doi: $10.1038 /$ ni1084

2. Feld M, Garcia R, Buddenkotte J, Katayama S, Lewis K, Muirhead $\mathrm{G}$, et al. The pruritus- and TH2-associated cytokine IL-31 promotes growth of sensory nerves. J Allergy Clin Immunol. (2016) 138:5008. doi: 10.1016/j.jaci.2016.02.020

3. Furue M, Ulzii D, Vu YH, Tsuji G, Kido-Nakahara M, Nakahara T. Pathogenesis of atopic dermatitis: current paradigm. Iran J Immunol. (2019) 16:97-107. doi: 10.22034/IJI.2019.80253

4. Cornelissen C, Marquardt Y, Czaja K, Wenzel J, Frank J, LüscherFirzlaff J, et al. IL-31 regulates differentiation and filaggrin expression in drug appears to hold new hope for patients whose treatment options are currently limited. Moreover, the administration of nemolizumab alongside topical agents closely mirrors the likely real-world clinical situation, in which many patients with atopic dermatitis are already treating their conditions, making the addition of nemolizumab into an ongoing treatment regimen relatively straightforward.

For several of the other diseases discussed herein, the underlying role of IL-31 in their pathophysiology remains unclear or unproven. The notable heterogeneity in IL-31 levels, ranging from $>1,000 \mathrm{pg} / \mathrm{mL}$ among patients with atopic dermatitis (40) to $<200 \mathrm{pg} / \mathrm{mL}$ in other diseases $(7,65,93$, 97), requires additional explanation, and further research is clearly warranted.

In addition to IL-31, there has been an explosion of recent interest in novel antipruritic drugs targeting other pathways thought to play role in the development or maintenance of itch, including opioid receptor agonists and antagonists, antibodies against various IL family members, and Janus kinase inhibitors $(15,120,121)$. It remains to be seen how many of these drugs will successfully demonstrate long-term effectiveness in controlling the signs and symptoms of pruritus, but it seems likely that the current management algorithms for pruritus will undergo extensive modification over the next few years.

In conclusion, IL-31 plays an important role in several inflammatory skin diseases, and treatment targeting IL-31 is expected to contribute meaningfully to the clinical management of a wide range of diseases.

\section{AUTHOR CONTRIBUTIONS}

KK and HI were involved in writing and critically reviewing the manuscript and both authors provided final approval of the manuscript for submission and agree to be accountable for the content.

\section{ACKNOWLEDGMENTS}

We thank Akihiko Ikoma, MD, Ph.D., of Maruho Co., Ltd., Osaka, Japan and Sally-Anne Mitchell, Ph.D., of McCANN HEALTH CMC, Japan, for providing editorial assistance, which was funded by Maruho Co., Ltd., Osaka, Japan.

human organotypic skin models. J Allergy Clin Immunol. (2012) 129:42633. doi: $10.1016 /$ j.jaci.2011.10.042

5. Zhang Q, Putheti P, Zhou Q, Liu Q, Gao W. Structures and biological functions of IL-31 and IL-31 receptors. Cytokine Growth Factor Rev. (2008) 19:347-56. doi: 10.1016/j.cytogfr.2008.08.003

6. Park K, Mori T, Nakamura M, Tokura Y. Increased expression of mRNAs for IL-4, IL-17, IL-22 and IL-31 in skin lesions of subacute and chronic forms of prurigo. Eur J Dermatol. (2011) 21:135-6. doi: 10.1684/ejd.2010. 1196

7. Salao K, Sawanyawisuth K, Winaikosol K, Choonhakarn C, Chaowattanapanit S. Interleukin-31 and chronic pruritus of unknown origin. Biomark Insights. (2020) 15:1177271920940712. doi: 10.1177/1177271920940712

8. Bodoor K, Al-Qarqaz F, Heis LA, Alfaqih MA, Oweis AO, Almomani R, et al. IL-33/13 axis and IL-4/31 axis play distinct roles in inflammatory process and 
itch in psoriasis and atopic dermatitis. Clin Cosmet Investig Dermatol. (2020) 13:419-24. doi: 10.2147/CCID.S257647

9. Gonzales AJ, Fleck TJ, Humphrey WR, Galvan BA, Aleo MM, Mahabir SP, et al. IL-31-induced pruritus in dogs: a novel experimental model to evaluate anti-pruritic effects of canine therapeutics. Vet Dermatol. (2016) 27:34-e10. doi: 10.1111/vde.12280

10. Andrade A, Kuah CY, Martin-Lopez JE, Chua S, Shpadaruk $\mathrm{V}$, Sanclemente G, et al. Interventions for chronic pruritus of unknown origin. Cochrane Database Syst Rev. (2020) 1:CD013128. doi: 10.1002/14651858.CD013128.pub2

11. Pereira MP, Mittal A, Stander S. Current treatment strategies in refractory chronic pruritus. Curr Opin Pharmacol. (2019) 46:1-6. doi: 10.1016/j.coph.2018.11.007

12. Furue M, Yamamura K, Kido-Nakahara M, Nakahara T, Fukui Y. Emerging role of interleukin-31 and interleukin-31 receptor in pruritus in atopic dermatitis. Allergy. (2018) 73:29-36. doi: 10.1111/all.13239

13. Singh B, Jegga AG, Shanmukhappa KS, Edukulla R, Khurana Hershey GH, Medvedovic M, et al. IL-31-driven skin remodeling involves epidermal cell proliferation and thickening that lead to impaired skin-barrier function. PLoS ONE. (2016) 11:e0161877. doi: 10.1371/journal.pone.0161877

14. Bagci IS, Ruzicka T. IL-31: a new key player in dermatology and beyond. $J$ Allergy Clin Immunol. (2018) 141:858-66. doi: 10.1016/j.jaci.2017.10.045

15. Erickson S, Heul AV, Kim BS. New and emerging treatments for inflammatory itch. Ann Allergy Asthma Immunol. (2020) 1:S1081206. doi: $10.1016 /$ j.anai.2020.05.028

16. Nygaard U, Vestergaard C, Deleuran M. Emerging treatment options in atopic dermatitis: systemic therapies. Dermatology. (2017) 233:34457. doi: $10.1159 / 000484406$

17. Gangemi S, Quartuccio S, Casciaro M, Trapani G, Minciullo PL, Imbalzano E. Interleukin 31 and skin diseases: a systematic review. Allergy Asthma Proc. (2017) 38:401-8. doi: 10.2500/aap.2017.38.4080

18. Nakashima C, Otsuka A, Kabashima K. Interleukin-31 and interleukin-31 receptor: new therapeutic targets for atopic dermatitis. Exp Dermatol. (2018) 27:327-31. doi: 10.1111/exd.13533

19. Wong $\mathrm{LS}, \mathrm{Wu} \mathrm{T}$, Lee $\mathrm{CH}$. Inflammatory and noninflammatory itch: implications in pathophysiology-directed treatments. Int J Mol Sci. (2017) 18:1485. doi: 10.3390/ijms 18071485

20. Hawro T, Przybylowicz K, Spindler M, PsyM MH, Steć M, Altrichter S, et al. The characteristics and impact of pruritus in adult dermatologic patients: a prospective, cross-sectional study. J Am Acad Dermatol. (2020). doi: 10.1016/j.jaad.2020.08.035. [Epub ahead of print].

21. Kini SP, Delong LK, Veledar E, Mckenzie-Brown AM, Schaufele M, Chen SC. The impact of pruritus on quality of life: the skin equivalent of pain. Arch Dermatol. (2011) 147:1153-6. doi: 10.1001/archdermatol.2011.178

22. Whang KA, Khanna R, Williams KA, Mahadevan V, Semenov Y, Kwatra SG. Health-related quality of life and economic burden of chronic pruritus. J Invest Dermatol. (2020). doi: 10.1016/j.jid.2020.08.020. [Epub ahead of print].

23. Silverberg JI, Gelfand JM, Margolis DJ, Boguniewicz M, Fonacier L, Grayson $\mathrm{M}$, et al. Patient burden and quality of life in atopic dermatitis in US adults: a population-based cross-sectional study. Ann Allergy Asthma Immunol. (2018) 121:340-7. doi: 10.1016/j.anai.2018.07.006

24. Jafferany M, Davari ME. Itch and psyche: psychiatric aspects of pruritus. Int J Dermatol. (2019) 58:3-23. doi: 10.1111/ijd.14081

25. Lee HG, Stull C, Yosipovitch G. Psychiatric disorders and pruritus. Clin Dermatol. (2017) 35:273-80. doi: 10.1016/j.clindermatol.2017.01.008

26. Chee A, Branca L, Jeker F, Vogt DR, Schwegler S, Navarini A, et al. When life is an itch: what harms, helps, and heals from the patients' perspective? Differences and similarities among skin diseases. Dermatol Ther. (2020) 33:e13606. doi: 10.1111/dth.13606

27. Hawro T, Hawro M, Zalewska-Janowska A, Weller K, Metz M, Maurer M. Pruritus and sleep disturbances in patients with psoriasis. Arch Dermatol Res. (2020) 312:103-11. doi: 10.1007/s00403-019-01998-7

28. Ramirez FD, Chen S, Langan SM, Prather AA, McCulloch CE, Kidd SA, et al. Association of atopic dermatitis with sleep quality in children. JAMA Pediatr. (2019) 173:e190025. doi: 10.1001/jamapediatrics.2019.0025

29. Xerfan EMS, Tomimori J, Andersen ML, Tufik S, Facina AS. Sleep disturbance and atopic dermatitis: a bidirectional relationship? Med Hypotheses. (2020) 140:109637. doi: 10.1016/j.mehy.2020.109637
30. Patel SP, Khanna R, Choi J, Williams KA, Roh YS, Hong MS, et al. Sleep disturbance in adults with chronic pruritic dermatoses is associated with increased C-reactive protein levels. J Am Acad Dermatol. (2020) 84:265-72. doi: 10.1016/j.jaad.2020.08.059

31. Luk KM, Shaw FM, Zhang C, Culler SD, Chen SC. The annual direct and indirect health care costs for patients with chronic pruritus and their determining factors. J Invest Dermatol. (2020) 140:699701. doi: 10.1016/j.jid.2019.07.711

32. Guevara-Sangines E, Perez-Rojas D, Nevárez-Sida A, Aceves MA, Barrón-Tapia MT, Abaroa-Cantú FJ, et al. [The annual cost of medical care for patients with moderate to severe atopic dermatitis in Mexico. A multicenter study] (In Spanish). Rev Alerg Mex. (2020) 67:9-18. doi: 10.29262/ram.v67i1.700

33. Whang KA, Gabriel S, Chavda R, Kwatra SG. Emergency department utilization by patients with prurigo nodularis in the United States. J Am Acad Dermatol. (2020). doi: 10.1016/j.jaad.2020.06.1002. [Epub ahead of print].

34. Whang KA, Kang S, Kwatra SG. Inpatient burden of prurigo nodularis in the United States. Medicines. (2019) 6:88. doi: 10.3390/medicines6030088

35. Gibbs BF, Patsinakidis N, Raap U. Role of the pruritic cytokine IL-31 in autoimmune skin diseases. Front Immunol. (2019) 10:1383. doi: 10.3389/fimmu.2019.01383

36. Arai I, Tsuji M, Miyagawa K, Takeda H, Akiyama N, Saito S. Repeated administration of IL-31 upregulates IL-31 receptor A (IL-31RA) in dorsal root ganglia and causes severe itch-associated scratching behaviour in mice. Exp Dermatol. (2015) 24:75-8. doi: 10.1111/exd.12587

37. Grimstad O, Sawanobori Y, Vestergaard C, Bisborough J, Oslen UB, Grønhøj-Larsen C, et al. Anti-interleukin-31-antibodies ameliorate scratching behaviour in NC/Nga mice: a model of atopic dermatitis. Exp Dermatol. (2009) 18:35-43. doi: 10.1111/j.1600-0625.2008.00766.x

38. Kasutani K, Fujii E, Ohyama S, Adachi H, HasegawanM, Kitamura H, et al. Anti-IL-31 receptor antibody is shown to be a potential therapeutic option for treating itch and dermatitis in mice. Br J Pharmacol. (2014) 171:5049-58. doi: 10.1111/bph.12823

39. Byeon JH, Yoon W, Ahn SH, Lee HS, Kim S, Yoo Y. Correlation of serum interleukin-31 with pruritus and blood eosinophil markers in children with atopic dermatitis. Allergy Asthma Proc. (2020) 41:5965. doi: 10.2500/aap.2020.41.190016

40. Ezzat MH, Hasan ZE, Shaheen KY. Serum measurement of interleukin31 (IL-31) in paediatric atopic dermatitis: elevated levels correlate with severity scoring. J Eur Acad Dermatol Venereol. (2011) 25:3349. doi: 10.1111/j.1468-3083.2010.03794.x

41. Lu J, Wu K, Zeng Q, Xiang Y, Gao L, Huang J. Serum interleukin-31 level and pruritus in atopic dermatitis: a meta-analysis. Zhong Nan Da Xue Xue Bao Yi Xue Ban. (2018) 43:124-30. doi: 10.11817/j.issn.1672-7347.2018. 02.003

42. Otsuka A, Tanioka M, Nakagawa Y, Honda T, Ikoma A, Miyachi Y, et al. Effects of cyclosporine on pruritus and serum IL-31 levels in patients with atopic dermatitis. Eur J Dermatol. (2011) 21:8167. doi: $10.1684 /$ ejd.2011.1470

43. Saleem MD, Oussedik E, D’amber V, Feldman SR. Interleukin-31 pathway and its role in atopic dermatitis: a systematic review. J Dermatol Treat. (2017) 28:591-9. doi: 10.1080/09546634.2017.1290205

44. Cevikbas F, Wang X, Akiyama T, Kempkes C, Savinko T, Antal A, et al. A sensory neuron-expressed IL-31 receptor mediates T helper cell-dependent itch: Involvement of TRPV1 and TRPA1. J Allergy Clin Immunol. (2014) 133:448-60. doi: 10.1016/j.jaci.2013.10.048

45. Bilsborough J, Leung DY, Maurer M, Howell M, Boguniewicz M, Yao L, et al. IL-31 is associated with cutaneous lymphocyte antigen-positive skin homing $\mathrm{T}$ cells in patients with atopic dermatitis. J Allergy Clin Immunol. (2006) 117:418-25. doi: 10.1016/j.jaci.2005.10.046

46. Zeidler C, Tsianakas A, Pereira M, Stander H, Yosipovitch G, Stander S. Chronic prurigo of nodular type: a review. Acta Derm Venereol. (2018) 98:173-9. doi: 10.2340/00015555-2774

47. Sonkoly E, Muller A, Lauerma AI, Pivarcsi A, Soto H, Kemeny L, et al. IL-31: a new link between $\mathrm{T}$ cells and pruritus in atopic skin inflammation. J Allergy Clin Immunol. (2006) 117:411-7. doi: 10.1016/j.jaci.2005.10.033

48. Armstrong AW, Read C. Pathophysiology, clinical presentation, and treatment of psoriasis: a review. JAMA. (2020) 323:194560. doi: 10.1001/jama.2020.4006 
49. Narbutt J, Olejniczak I, Sobolewska-Sztychny D, Sysa-Jedrzejowska A, Słowik-Kwiatkowska I, Howro T, et al. Narrow band ultraviolet B irradiations cause alteration in interleukin-31 serum level in psoriatic patients. Arch Dermatol Res. (2013) 305:191-5. doi: 10.1007/s00403-012-1293-6

50. Chen J, Li C, Li H, Yu H, Zhang X, Yan M, et al. Identification of a TH 2high psoriasis cluster based on skin biomarker analysis in a Chinese psoriasis population. J Eur Acad Dermatol Venereol. (2020). doi: 10.1111/jdv.16563. [Epub ahead of print].

51. Neis MM, Peters B, Dreuw A, Wenzel J, Bieber T, Mauch C, et al. Enhanced expression levels of IL-31 correlate with IL-4 and IL-13 in atopic and allergic contact dermatitis. J Allergy Clin Immunol. (2006) 118:9307. doi: 10.1016/j.jaci.2006.07.015

52. Czarnecka-Operacz M, Polańska A, Klimańska M, Teresiak-Mikołajczak E, Molińska-Glura M, Adamski Z, et al. Itching sensation in psoriatic patients and its relation to body mass index and IL-17 and IL-31 concentrations. Postepy Dermatol Alergol. (2015) 32:426-30. doi: 10.5114/pdia.2015.56097

53. Bobrowicz M, Fassnacht C, Ignatova D, Chang YT, Dimitriou F, Guenova E. Pathogenesis and therapy of primary cutaneous T-cell lymphoma: Collegium Internationale Allergologicum (CIA) update 2020. Int Arch Allergy Immunol. (2020) 181:733-45. doi: 10.1159/000509281

54. Nattkemper LA, Martinez-Escala ME, Gelman AB, Singer EM, Rook AH, Guitart J, et al. Cutaneous T-cell lymphoma and pruritus: the expression of IL-31 and its receptors in the skin. Acta Derm Venereol. (2016) 96:8948. doi: 10.2340/00015555-2417

55. Ohmatsu H, Sugaya M, Suga H, Morimura S, Miyagaki T, Kai H, et al. Serum IL-31 levels are increased in patients with cutaneous T-cell lymphoma. Acta Derm Venereol. (2012) 92:282-3. doi: 10.2340/00015555-1345

56. Mobs M, Gryzik S, Haidar A, Humme D, Beyer M, Vandersee S. Analysis of the IL-31 pathway in Mycosis fungoides and Sezary syndrome. Arch Dermatol Res. (2015) 307:479-85. doi: 10.1007/s00403-014-1527-x

57. Singer EM, Shin DB, Nattkemper LA, Benoit BM, Klein RS, Didigu CA, et al. IL-31 is produced by the malignant T-cell population in cutaneous Tcell lymphoma and correlates with CTCL pruritus. J Invest Dermatol. (2013) 133:2783-5. doi: 10.1038/jid.2013.227

58. Malek M, Glen J, Rebala K, Kowalczyk A, Sobjanek M, Nowicki R, et al. Il-31 does not correlate to pruritus related to early stage cutaneous Tcell lymphomas but is involved in pathogenesis of the disease. Acta Derm Venereol. (2015) 95:283-8. doi: 10.2340/00015555-1958

59. Olszewska B, Sokolowska-Wojdylo M, Lakomy J, Nowicki RJ. The ambiguous pruritogenic role of interleukin-31 in cutaneous T-cell lymphomas in comparison to atopic dermatitis: a review. Postepy Dermatol Alergol. (2020) 37:319-25. doi: 10.5114/ada.2020.96260

60. Dumont S, Péchère $M$, Toutous Trellu L. Chronic prurigo: an unusual presentation of Hodgkin lymphoma. Case Rep Dermatol. (2018) 10:1226. doi: 10.1159/000489161

61. Ferretti E, Hohaus S, Di Napoli A, Belmonte B, Cuccaro A, Cupelli E, et al. Interleukin-31 and thymic stromal lymphopoietin expression in plasma and lymph node from Hodgkin lymphoma patients. Oncotarget. (2017) 8:85263-75. doi: 10.18632/oncotarget.19665

62. Zeng Q, Gupta A, Xin L, Poon M, Schwarz H. Plasma factors for the differentiation of Hodgkin's lymphoma and diffused large B cell lymphoma and for monitoring remission. J Hematol. (2019) 8:4754. doi: 10.14740/jh499

63. Kfoury LW, Jurdi MA. Uremic pruritus. J Nephrol. (2012) 25:64452. doi: 10.5301/jn.5000039

64. Mettang T, Kremer AE. Uremic pruritus. Kidney Int. (2015) 87:68591. doi: $10.1038 / \mathrm{ki} .2013 .454$

65. Oweis AO, Al-Qarqaz F, Bodoor K, Heis L, Alfaqih MA, Almomani $\mathrm{R}$, et al. Elevated interleukin 31 serum levels in hemodialysis patients are associated with uremic pruritus. Cytokine. (2020) 138:155369. doi: 10.1016/j.cyto.2020.155369

66. Ko MJ, Peng YS, Chen HY, Hsu SP, Pai MF, Yang JY, et al. Interleukin-31 is associated with uremic pruritus in patients receiving hemodialysis. $\mathrm{J} \mathrm{Am}$ Acad Dermatol. (2014) 71:1151-9 e1151. doi: 10.1016/j.jaad.2014.08.004

67. Kremer AE, Namer B, Bolier R, Fischer MJ, Oude Elferink RP, Beuers U. Pathogenesis and management of pruritus in PBC and PSC. Dig Dis. (2015) 33 Suppl 2:164-75. doi: 10.1159/000440829

68. Basile F, Santamaria A, Mannucci C, Rizzo L, Gangemi S, D'anna R, et al. Interleukin 31 is involved in intrahepatic cholestasis of pregnancy. J Matern
Fetal Neonatal Med. (2017) 30:1124-7. doi: 10.1080/14767058.2016.12 05025

69. Ming D, Yu X, Guo R, Deng Y, Li J, Lin C, et al. Elevated TGF-beta1/IL31 pathway is associated with the disease severity of hepatitis B virus-related liver cirrhosis. Viral Immunol. (2015) 28:209-16. doi: 10.1089/vim.2014.0142

70. Raap U, Gehring M, Kleiner S, Rüdrich U, Eiz-Vesper B, Haas H, et al. Human basophils are a source of - and are differentially activated by - IL-31. Clin Exp Allergy. (2017) 47:499-508. doi: 10.1111/cea.12875

71. Raap U, Wieczorek D, Gehring M, Pauls I, Ständer S, Kapp A, et al. Increased levels of serum IL-31 in chronic spontaneous urticaria. Exp Dermatol. (2010) 19:464-6. doi: 10.1111/j.1600-0625.2010.01067.x

72. Rüdrich U, Gehring $M$, Papakonstantinou E, Illerhaus A, Engmann J, Kapp A, et al. Eosinophils are a major source of interleukin-31 in bullous pemphigoid. Acta Derm Venereol. (2018) 98:766-71. doi: 10.2340/00015555-2951

73. Salz M, Haeberle S, Hoffmann J, Enk AH, Hadaschik EN. Elevated IL31 serum levels in bullous pemphigoid patients correlate with eosinophil numbers and are associated with BP180-IgE. J Dermatol Sci. (2017) 87:30911. doi: 10.1016/j.jdermsci.2017.07.019

74. Kulczycka-Siennicka L, Cynkier A, Waszczykowska E, Wozniacka A, Zebrowska A. The role of interleukin-31 in pathogenesis of itch and its intensity in a course of bullous pemphigoid and dermatitis herpetiformis. Biomed Res Int. (2017) 2017:5965492. doi: 10.1155/2017/59 65492

75. Morais KL, Miyamoto D, Orfali RL, Maruta CW, Santi CG, Sotto MN, et al. Increased expression of in situ IL-31RA and circulating CXCL8 and CCL2 in pemphigus herpetiformis suggests participation of the IL-31 family in the pathogenesis of the disease. J Eur Acad Dermatol Venereol. (2020) 34:2890-97. doi: $10.1111 / j d v .16730$

76. Martin SF, Rustemeyer T, Thyssen JP. Recent advances in understanding and managing contact dermatitis. F1000Res. (2018) 7:810. doi: 10.12688/f1000research.13499.1

77. Guarneri F, Minciullo PL, Mannucci C, Calapai F, Saitta S, Cannavò SP, et al. IL-31 and IL-33 circulating levels in allergic contact dermatitis. Eur Ann Allergy Clin Immunol. (2015) 47:156-8.

78. Takamori A, Nambu A, Sato K, Yamaguchi S, Matsuda K, Numata T, et al. IL-31 is crucial for induction of pruritus, but not inflammation, in contact hypersensitivity. Sci Rep. (2018) 8:6639. doi: 10.1038/s41598-018-25094-4

79. Dewane ME, Waldman R, Lu J. Dermatomyositis: clinical features and pathogenesis. J Am Acad Dermatol. (2020) 82:267-81. doi: 10.1016/j.jaad.2019.06.1309

80. Shirani Z, Kucenic MJ, Carroll CL, Fleischer AB Jr, Feldman SR, Yosipovitch G, et al. Pruritus in adult dermatomyositis. Clin Exp Dermatol. (2004) 29:273-6. doi: 10.1111/j.1365-2230.2004.01510.x

81. Kim HJ, Zeidi M, Bonciani D, Pena SM, Tiao J, Sahu S, et al. Itch in dermatomyositis: the role of increased skin interleukin-31. $\mathrm{Br}$ J Dermatol. (2018) 179:669-78. doi: 10.1111/bjd.16498

82. Kim BS, Berger TG, Yosipovitch G. Chronic pruritus of unknown origin (CPUO): uniform nomenclature and diagnosis as a pathway to standardized understanding and treatment. J Am Acad Dermatol. (2019) 81:12234. doi: 10.1016/j.jaad.2019.06.038

83. Welz-Kubiak K, Kobuszewska A, Reich A. IL-31 is overexpressed in lichen planus but its level does not correlate with pruritus severity. J Immunol Res. (2015) 2015:854747. doi: 10.1155/2015/854747

84. Dousset L, Seneschal J, Boniface K, Charreau S, Ezzedine K, Milpied B, et al. A Th2 cytokine interleukin-31 signature in a case of sporadic lichen amyloidosis. Acta Derm Venereol. (2015) 95:223-4. doi: 10.2340/00015555-1829

85. Tey HL, Cao T, Nattkemper LA, Tan VW, Pramono ZA, Yosipovitch G. Pathophysiology of pruritus in primary localized cutaneous amyloidosis. $\mathrm{Br}$ J Dermatol. (2016) 174:1345-50. doi: 10.1111/bjd.14391

86. Fawzi MMT, Gawdat HI, Mahmoud SB, El-Hawary MS, Rashed LA, Esmat SM. Fractional carbon dioxide laser is effective in amelioration of pruritus in primary cutaneous amyloidosis: a clinical and biochemical study. Lasers Surg Med. (2020). doi: 10.1002/lsm.23313. [Epub ahead of print].

87. Hashimoto T, Kursewicz CD, Fayne RA, Nanda S, Shah SM, Nattkemper $\mathrm{L}$, et al. Mechanisms of itch in stasis dermatitis: significant role of IL-31 from macrophages. J Invest Dermatol. (2020) 140:850-9 e853. doi: 10.1016/j.jid.2019.09.012 
88. Yaseen B, Lopez H, Taki Z, Zafar S, Rosario H, Abdi BA, et al. Interleukin-31 promotes pathogenic mechanisms underlying skin and lung fibrosis in scleroderma. Rheumatology. (2020) 59:2625-36. doi: 10.1093/rheumatology/keaa195

89. Xu J, Zanvit P, Hu L, Tseng PY, Liu N, Wang F, et al. The cytokine TGF-beta induces interleukin-31 expression from dermal dendritic cells to activate sensory neurons and stimulate wound itching. Immunity. (2020) 53:371-83. doi: 10.1016/j.immuni.2020.06.023

90. Jawa RS, Chattopadhyay S, Tracy E, Wang Y, Huntoon K, Dayton MT, et al. Regulated expression of the IL-31 receptor in bronchial and alveolar epithelial cells, pulmonary fibroblasts, and pulmonary macrophages. $J$ Interferon Cytokine Res. (2008) 28:207-19. doi: 10.1089/jir.2007.0057

91. Ip WK, Wong CK, Li ML, Li PW, Cheung PF, Lam CW. Interleukin31 induces cytokine and chemokine production from human bronchial epithelial cells through activation of mitogen-activated protein kinase signalling pathways: Implications for the allergic response. Immunology. (2007) 122:532-41. doi: 10.1111/j.1365-2567.2007.02668.x

92. Lei Z, Liu G, Huang Q, Lv M, Zu R, Zhang GM, et al. SCF and IL-31 rather than IL-17 and BAFF are potential indicators in patients with allergic asthma. Allergy. (2008) 63:327-32. doi: 10.1111/j.1398-9995.2007.01566.x

93. Lai $\mathrm{T}$, Wu D, Li W, Chen M, Yi Z, Huang D, et al. Interleukin-31 expression and relation to disease severity in human asthma. Sci Rep. (2016) 6:22835. doi: 10.1038/srep22835

94. Dambacher J, Beigel F, Seiderer J, Haller D, Göke B, Auernhammer CJ, et al. Interleukin 31 mediates MAP kinase and STAT1/3 activation in intestinal epithelial cells and its expression is upregulated in inflammatory bowel disease. Gut. (2007) 56:1257-65. doi: 10.1136/gut.2006.118679

95. Verstockt S, Verstockt B, Vermeire S. Oncostatin $M$ as a new diagnostic, prognostic and therapeutic target in inflammatory bowel disease (IBD). Expert Opin Ther Targets. (2019) 23:94354. doi: 10.1080/14728222.2019.1677608

96. De Martinis M, Sirufo MM, Suppa M, Ginaldi L. IL-33/IL-31 axis in osteoporosis. Int J Mol Sci. (2020) 21:1239. doi: 10.3390/ijms21041239

97. Ginaldi L, De Martinis M, Ciccarelli F, Saitta S, Imbesi S, Mannucci C, et al. Increased levels of interleukin 31 (IL-31) in osteoporosis. BMC Immunol. (2015) 16:60. doi: 10.1186/s12865-015-0125-9

98. Mannucci C, Calapai G, Gangemi S. Commentary: circulatory pattern of cytokines, adipokines and bone markers in postmenopausal women with low BMD. Front Immunol. (2019) 10:2666. doi: 10.3389/fimmu.2019.02666

99. He A, Feldman SR, Fleischer AB Jr. An assessment of the use of antihistamines in the management of atopic dermatitis. J Am Acad Dermatol. (2018) 79:92-6. doi: 10.1016/j.jaad.2017.12.077

100. Yang TB, Kim BS. Pruritus in allergy and immunology. J Allergy Clin Immunol. (2019) 144:353-60. doi: 10.1016/j.jaci.2019.06.016

101. Metz M. Treatments for chronic pruritus outside of the box. Exp Dermatol. (2019) 28:1476-81. doi: 10.1111/exd.14007

102. Pereira MP, Zeidler C, Storck M, Agelopoulos K, Philipp-Dormston WG, Zink A, et al. Challenges in clinical research and care in pruritus. Acta Derm Venereol. (2020) 100:adv00028. doi: 10.2340/00015555-3348

103. Kabashima K, Matsumura T, Komazaki H, Kawashima M, Nemolizumab-Jp01 Study Group. Trial of nemolizumab and topical agents for atopic dermatitis with pruritus. N Engl J Med. (2020) 383:141-50. doi: 10.1056/NEJMoa1917006

104. Ständer S, Yosipovitch G, Legat FJ, Lacour JP, Paul C, Narbutt J, et al. Trial of nemolizumab in moderate-to-severe prurigo nodularis. N Engl J Med. (2020) 382:706-16. doi: 10.1056/NEJMoa1908316

105. Vixarelimab. Kiniksa Pharmaceuticals Corp. Lexington, MA (2020). Available online at: https://www.kiniksa.com/our-pipeline/vixarelimab/ (accessed November 2020).

106. Oyama S, Kitamura H, Kuramochi T, Higuchi Y, Matsushita H, Suzuki T, et al. Cynomolgus monkey model of interleukin-31induced scratching depicts blockade of human interleukin-31 receptor A by a humanized monoclonal antibody. Exp Dermatol. (2018) 27:14-21. doi: 10.1111/exd.13236

107. Mizuno T, Kanbayashi S, Okawa T, Maeda S, Okuda M. Molecular cloning of canine interleukin-31 and its expression in various tissues. Vet Immunol Immunopathol. (2009) 131:140-3. doi: 10.1016/j.vetimm.2009.03.014
108. Gonzales AJ, Humphrey WR, Messamore JE, Fleck TJ, Fici GJ, Shelly JA, et al. Interleukin-31: Its role in canine pruritus and naturally occurring canine atopic dermatitis. Vet Dermatol. (2013) 24:48-53. doi: 10.1111/j.1365-3164.2012.01098.x

109. Michels GM, Walsh KF, Kryda KA, Martinon OM, Mahabir SP, Hoevers JD, et al. A blinded, randomized, placebo-controlled trial of the safety of lokivetmab (ZTS-00103289), a caninized anti-canine IL-31 monoclonal antibody in client-owned dogs with atopic dermatitis. Vet Dermatol. (2016) 27:505-e136. doi: 10.1111/vde.12364

110. Souza CP, Rosychuk RaW, Contreras ET, Schissler JR, Simpson AC. A retrospective analysis of the use of lokivetmab in the management of allergic pruritus in a referral population of 135 dogs in the western USA. Vet Dermatol. (2018) 29:489-e164. doi: 10.1111/vde.12682

111. Szczepanik MP, Popiel J, Cekiera A, Pomorska-Handwerker D, Karaś-Tecza J, Sciskalska M, et al. Evaluation of the clinical efficiency of lokivetmab in client privately owned atopic dogs - multicenter study. Pol J Vet Sci. (2020) 23:191-5. doi: 10.24425/pjvs.2020.132765

112. Meichner K, Kiupel M, Kasantikul T, Rakich P, Banovic F. Lokivetmab therapy for pruritus in a dog with cutaneous mastocytosis. Vet Dermatol. (2019) 30:73-e22. doi: 10.1111/vde.12702

113. Nemoto O, Furue M, Nakagawa H, Shiramoto M, Hanada R, Matsuki S, et al. The first trial of CIM331, a humanized antihuman interleukin-31 receptor A antibody, in healthy volunteers and patients with atopic dermatitis to evaluate safety, tolerability and pharmacokinetics of a single dose in a randomized, double-blind, placebo-controlled study. Br J Dermatol. (2016) 174:296-304. doi: 10.1111/bjd.14207

114. Kabashima K, Furue M, Hanifin JM, Pulka G, Wollenberg A, Galus R, et al. Nemolizumab in patients with moderate-to-severe atopic dermatitis: randomized, phase II, long-term extension study. J Allergy Clin Immunol. (2018) 142:1121-30. doi: 10.1016/j.jaci.2018.03.018

115. Ruzicka T, Hanifin JM, Furue M, Pulka G, Mlynarczyk I, Wollenberg A, et al. Anti-interleukin-31 receptor A antibody for atopic dermatitis. N Engl J Med. (2017) 376:826-35. doi: 10.1056/NEJMoa1606490

116. Silverberg JI, Pinter A, Pulka G, Poulin Y, Bouaziz JD, Wollenberg A, et al. Phase $2 \mathrm{~b}$ randomized study of nemolizumab in adults with moderatesevere atopic dermatitis and severe pruritus. J Allergy Clin Immunol. (2020) 145:173-82. doi: 10.1016/j.jaci.2019.08.013

117. Mihara R, Kabashima K, Furue M, Nakano M, Ruzicka T. Nemolizumab in moderate to severe atopic dermatitis: an exploratory analysis of work productivity and activity impairment in a randomized phase II study. $J$ Dermatol. (2019) 46:662-71. doi: 10.1111/1346-8138.14934

118. Silverberg JI, Hinami K, Trick WE, Cella D. Itch in the general internal medicine setting: a cross-sectional study of prevalence and quality-of-life effects. Am J Clin Dermatol. (2016) 17:681-90. doi: 10.1007/s40257-016-0215-3

119. Furue M, Chiba T, Tsuji G, Ulzii D, Kido-Nakahara M, Nakahara $\mathrm{T}$, et al. Atopic dermatitis: immune deviation, barrier dysfunction, IgE autoreactivity and new therapies. Allergol Int. (2017) 66:398403. doi: 10.1016/j.alit.2016.12.002

120. Puar N, Chovatiya R, Paller AS. New treatments in atopic dermatitis. Ann Allergy Asthma Immunol. (2021) 126:21-31. doi: 10.1016/j.anai.2020.08.016

121. Reszke R, Krajewski P, Szepietowski JC. Emerging therapeutic options for chronic pruritus. Am J Clin Dermatol. (2020) 21:601-18. doi: 10.1007/s40257-020-00534-y

Conflict of Interest: $\mathrm{KK}$ has received grants from Japan Tobacco Inc., Kyowa Kirin, LEO Pharma, Maruho, Mitsubishi Tanabe Pharma, ONO PHARMACEUTICAL, POLA PHARMA, TAIHO PHARMA, Torii Pharmaceutical, and The Procter \& Gamble Company, and has received personal fees from Maruho. HI has received grants from Maruho.

Copyright (๑) 2021 Kabashima and Irie. This is an open-access article distributed under the terms of the Creative Commons Attribution License (CC BY). The use, distribution or reproduction in other forums is permitted, provided the original author(s) and the copyright owner(s) are credited and that the original publication in this journal is cited, in accordance with accepted academic practice. No use, distribution or reproduction is permitted which does not comply with these terms. 